\title{
Degradation of nitro-based pharmaceuticals by UV photolysis: Kinetics and simultaneous reduction on halonitromethanes formation potential
}

\author{
Huiyu Dong ${ }^{\text {a }}$, Zhimin Qiang ${ }^{\text {a, }}{ }^{*}$, Junfeng Lian ${ }^{\text {b }}$, Jiuhui Qu ${ }^{\text {a }}$ \\ ${ }^{a}$ Key Laboratory of Drinking Water Science and Technology, Research Center for Eco-Environmental Sciences, University of Chinese Academy of Sciences, \\ Chinese Academy of Sciences, 18 Shuang-qing Road, Beijing 100085, China \\ ${ }^{\mathrm{b}}$ School of Architectural, Surveying and Mapping Engineering, Jiangxi University of Science and Technology, 86 Hong-qi Road, Ganzhou 341000, China
}

\section{A R T I C L E I N F O}

\section{Article history:}

Received 18 January 2017

Received in revised form

17 April 2017

Accepted 19 April 2017

Available online 19 April 2017

Keywords:

UV photolysis

Nitro-based pharmaceuticals

Kinetics

Halonitromethanes formation potential

\begin{abstract}
A B S T R A C T
This study investigated the degradation kinetics and halonitromethanes formation potential (HNMsFP) of two nitro-based pharmaceuticals (i.e., ranitidine (RNTD) and nizatidine (NZTD)) during ultraviolet (UV) photolysis. It was found that the degradation kinetics of RNTD and NZTD exhibited pH-dependent trends, in accordance with their deprotonation equilibria. The neutral species of RNTD and NZTD were more photo-reactive than their corresponding deprotonated species, with their specific fluence-based firstorder rate constants varying in the range of 5.64-31.90 $\mathrm{m}^{2} \mathrm{E}^{-1}$. Both the RNTD and NZTD were prone precursors of HNMs (with molar yields of $5.6 \pm 0.3 \%$ and $4.7 \pm 0.4 \%$, respectively at $\mathrm{pH} 7.0$ ). Acidic and neutral circumstances facilitated the HNMs formation. The UV photolysis of RNTD and NZTD could reduce their HNMsFP simultaneously. Positive linear relationships between residual RNTD or NZTD concentration and HNMsFP were observed and the denitration during the UV photolysis accounted for the HNMsFP reduction. With the mandatory UV disinfection fluences in China (i.e. $20-80 \mathrm{~mJ} \mathrm{~cm}{ }^{-2}$ ), the effective abatement of RNTD and NZTD and their HNMsFP could not be fully achieved, highlighting the necessity of increasing UV fluence or developing UV-based advanced oxidation process in future.
\end{abstract}

(C) 2017 Elsevier Ltd. All rights reserved.

\section{Introduction}

Formation of toxic nitrogenous disinfection by-products ( $\mathrm{N}$ DBPs) is a growing concern for water utilities using impaired source waters with wastewater effluent discharges or algal blooms due to elevated concentrations of dissolved organic nitrogen as N-DBP precursors (Fang et al., 2010; Chu et al., 2014). HNMs are one class of emerging N-DBPs in drinking water, which have drawn public concern due to their high toxicity (Bond et al., 2014). Among 50 high priority DBPs monitored in a 2000-2002 U.S. nationwide survey at drinking water treatment plants (DWTPs), the cytotoxicity of HNMs with in vitro mammalian cell tests could be several orders of magnitude higher than currently regulated trihalomethanes (THMs) and haloacetic acids (HAAs) (Weinberg et al., 2002). Generally, the chemical structure of HNMs contains a nitrogroup and different halogens on the $\alpha$-carbon including mono-, di-

\footnotetext{
* Corresponding author.

E-mail address: qiangz@rcees.ac.cn (Z. Qiang).
}

and tri-halogenated species (Plewa et al., 2004).

Continued efforts have been made to identify the major HNM precursors and control HNMs formation by optimized pretreatment and disinfection processes for water and wastewater. After analyzing the HNM concentrations in 20 drinking water supply systems in the United Kingdoms, Bond et al. (2015) found that the summed concentration of HNMs was not correlated with that of THMs or HAAs. Yang et al. (2012) observed that the trichloronitromethane (TCNM) formation was higher during chlorination than chloramination, when spiked with 31 organic nitrogen compounds. During chloramination, both organic nitrogen and nitrate contributed to the nitrogen source of HNMs, while monochloramine did not contribute to the nitrogen source of TCNM. Nitro-based and amino-based compounds are considered as the direct and indirect precursors of HNMs, respectively (Bond et al., 2012; Deng et al., 2014).

Belonging to the group of histamine-2 blockers, ranitidine (RNTD) and nizatidine (NZTD) are prescribed worldwide as gastrointestinal drugs, which can reduce the amount of acid producers in stomach (Wu et al., 2001). As RNTD and NZTD cannot be 
effectively removed in biological wastewater treatment process, both have been frequently detected in wastewater treatment plant (WWTP) effluents and receiving waters (Castiglioni et al., 2006; Radjenovic et al., 2009). The detected RNTD concentrations were reported in the range of $70-540 \mathrm{ng} \mathrm{L}^{-1}$ in primary effluents of WWTPs (Radjenovic et al., 2009) and around $10 \mathrm{ng} \mathrm{L}^{-1}$ in several surface waters (Kolpin et al., 2002). Apart from inducing adverse ecological consequences to receiving waters, the nitro-group of RNTD and NZTD may become the precursor of HNMs during disinfection.

Effective strategy for reducing the HNMs formation is removing the main nitrogen-containing precursors before chlorination. As conventional drinking water treatment processes (e.g., coagulation/ sedimentation and filtration) are ineffective in reducing lowmolecular-weight organic nitrogen precursors (Lee and Westerhoff, 2006; Chu et al., 2011), pre-oxidation with chlorine, ozone, and some other oxidants has been evaluated to decrease the HNMsFP by transforming some key structural moieties of HNM precursors (Wang et al., 2016). Unfortunately, the HNMs formation may be promoted after the attack of oxidant and/or radicals. For precursors containing an amine-group, the combined ultraviolet (UV)/chlorine treatment could oxidize the amine-group to a nitrogroup, which is always a rate-limiting step for the formation of HNMs (Deng et al., 2014). Ozonation also led to a promoted TCNM formation and primary and secondary alkyl amines are the predominant precursors (McCurry et al., 2016). UV irradiation has been recognized as a promising disinfection means because it neither requires additional chemical(s) nor impairs the aesthetic quality (e.g., taste and odor) of treated water and wastewater. However, little is known so far about the degradation of RNTD and NZTD by UV photolysis and the subsequent impact on the HNMsFP during chlorination is also largely unknown.

The objectives of this study were to: (1) determine the kinetic parameters of RNTD and NZTD degradation under UV (254 nm) irradiation; (2) clarify the effects of $\mathrm{pH}$ and chlorine concentration on the HNMsFP of RNTD and NZTD; and (3) determine the effect of UV photolysis on the subsequent HNMsFP of RNTD and NZTD during chlorination. It is expected to illustrate the behavior and fate of nitro-based pharmaceuticals during the disinfection of water and wastewater.

\section{Materials and methods}

\subsection{Materials}

Individual HNMs, including monochloronitromethane (MCNM), dichloronitromethane (DCNM) and TCNM, were all purchased from CanSyn Chem. Co. (BC, Canada). An internal standard, 1,2dibromopropane, was purchased from J\&K Chemical Co. (Beijing, China). RNTD and NZTD were purchased from Tokyo Chemical Industry Co. (Tokyo, Japan). High performance liquid chromatography (HPLC) grade methanol and acetonitrile were obtained from Thermo Fisher Scientific (NJ, USA), and formic acid ( $\geq 99.0 \%)$ from Dikma Technologies (CA, USA). All other chemicals, of at least analytical grade, were provided by Beijing Chemical Reagents Company (Beijing, China). All solutions were prepared in ultrapure water $(18.2 \mathrm{M} \Omega \mathrm{cm}$ ) produced by a Milli-Q system (Advantage A10, Millipore, MA, USA).

\subsection{Experimental procedures}

\subsubsection{UV photolysis system}

A cylindrical glass reactor (inner diameter (i.d.) $=10.0 \mathrm{~cm}$, height $=25.0 \mathrm{~cm}$ ) was used as the UV photolysis reactor with a working volume of $1.0 \mathrm{~L}$ (Fig. S1). The temperature of the UV system was controlled at $25{ }^{\circ} \mathrm{C}$ by circulating the water in the bath. A quartz tube (i.d. $=4.5 \mathrm{~cm}$ ) and one low pressure (LP) Hg UV lamps (Heraeus, GPH 212T5L/4, $10 \mathrm{~W}$ ) were fixed in the center of the UV reactor, which was magnetic mixed at the bottom of the reactor. The UV lamp was initially warmed up for about 30 min to ensure a relatively stable output. The photo flux $\left(\mathrm{I}_{0}\right)$ was determined to be $0.75 \mathrm{mE} \mathrm{s}^{-1}$ for kinetic tests via iodide-iodate chemical actinometry (Bolton and Linden, 2003). The effective path length (L) was determined to be $7.2 \mathrm{~cm}$ by measuring the photolysis rate of $\mathrm{H}_{2} \mathrm{O}_{2}$ (Garoma and Gurol, 2005). The average UV fluence rate was determined to be $2.1 \mathrm{~mW} \mathrm{~cm}^{-2}$ by atrazine actinometer and the UV photolysis experiments were conducted in triplicate.

The quantum yield $(\Phi)$ is a fundamental parameter that quantifies the photon efficiency of a photochemical reaction (Shu et al., 2013). For the analysis of $\Phi$ during the UV photolysis at $254 \mathrm{~nm}$, the aqueous solution to be irradiated was buffered with $10 \mathrm{mM}$ phosphate buffer. To verify the UV photolysis of RNTD and NZTD in real waters, three real waters including filtered water (FW) from a DWTP, river water (RW) and WWTP effluent water (WE) were sampled and filtered $(0.45 \mu \mathrm{m})$ prior to the UV photolysis. The addition of the stock solutions of RNTD and NZTD to the real water samples did not cause any substantial dilution $(<1 \%)$ of the water matrix components. A UV-vis spectrophotometer (DR5000, Hach, CA, USA) was used to measure the apparent molar absorptivity of RNTD and NZTD at $254 \mathrm{~nm}$. RNTD and NZTD concentrations ranged from 0 to $10 \mu \mathrm{M}$, and $\mathrm{pH}$ was controlled using $10 \mathrm{mM}$ phosphate buffer.

\subsubsection{HNMsFP test}

HNM precursors are diverse and may be amenable to different treatment processes based on their chemical structures. To evaluate the effectiveness of treatment techniques, HNM precursors can be measured using a HNMsFP test, which was conducted by chlorinating water containing precursors and measuring the amount of HNMs formed over $24 \mathrm{~h}$. The HNMsFP reduction is then quantified as the reduction in formation potential before and after the UV photolysis. HNMsFP tests were conducted in triplicate in the dark using $50 \mathrm{~mL}$ headspace-free screw-cap amber glass vials with PTFElined septa at $25^{\circ} \mathrm{C}$ for $24 \mathrm{~h}$.

\subsection{Analysis}

RNTD and NZTD concentrations were measured with an Agilent 1200 series HPLC (CA, USA) equipped with an Atlantis C18 column $(4.6 \times 250 \mathrm{~mm}, 5.0 \mu \mathrm{m}$; Waters, MA, USA) at an UV wavelength of 254 and $230 \mathrm{~nm}$, respectively. The mobile phase was a mixture of methanol/water $(65: 35, \mathrm{v} / \mathrm{v})$. The flow rate was set at $0.6 \mathrm{~mL} \mathrm{~min}{ }^{-1}$ and the injection volume was $50 \mu \mathrm{L}$. The temperature of the column was set at $25^{\circ} \mathrm{C}$. The formation of HNMs was analyzed after samples being extracted with methyl tert-butyl ether using a gas chromatograph (7890, Agilent, CA, USA) equipped with an HP 5 capillary column ( $30 \mathrm{~m} \times 0.25 \mathrm{~mm}, 0.25 \mu \mathrm{m}$, J\&W, USA) and an electronic capture detector using the modified USEPA method 551.1 (Munch and Hautman, 1995). $\mathrm{NO}_{2}^{-}$and $\mathrm{NO}_{3}^{-}$were analyzed by ion chromatography (IC) (ICS-2000, Dionex, CA, USA) with an AS19 column $(4 \times 250 \mathrm{~mm})$ and an eluent of $30 \mathrm{mM} \mathrm{KOH}$ at a flow rate of $1 \mathrm{~mL} \mathrm{~min}^{-1}$. Water samples were filtered $(0.45 \mu \mathrm{m})$ prior to chromatographic analysis and the injection volume was $20 \mu \mathrm{L}$. Chlorine concentration was determined using DPD colorimetry.

The transformation by-products (TBPs) of RNTD and NZTD were identified by ultra-performance liquid chromatography-tandem mass spectrometry (UPLC-MS/MS, Agilent 1290 Infinity LC, Agilent 6420 Triple Quad LC/MS detector, CA, USA) coupled with an Acquity CSH ${ }^{\mathrm{TM}} \mathrm{C} 18$ column $(2.1 \times 100 \mathrm{~mm}, 1.7 \mu \mathrm{m})$ (Waters, USA) The mobile phase consisted of $(A)$ formic acid/methanol $(1: 1000, v)$ 
v) $(1: 1000, v / v)$ and (B) formic acid/Milli-Q water $(1: 1000, v / v)$ pumped at a flow rate of $0.3 \mathrm{~mL} \mathrm{~min}^{-1}$. Elution gradient was programed as follows (\% of $A$, min): $(5,5),(30,25),(30,30),(90,40)$, $(90,42)$, and $(0,60)$. The injection volume was $20 \mu \mathrm{L}$. All samples were analyzed with both total ion chromatogram and selected ion monitoring modes.

\section{Results and discussion}

\subsection{Determination of molar absorption coefficients at $254 \mathrm{~nm}$}

Molar extinction coefficient $(\varepsilon)$ has been widely acknowledged as a significant parameter which strongly affects the UV photolysis rate. As shown in Fig. S2, the absorption spectrum of RNTD exhibits the maximum band at $229 \mathrm{~nm}$, and a weak band with a smooth maximum at $312 \mathrm{~nm}$, while the absorption spectrum of NZTD exhibits the maximum band with a maximum at $311 \mathrm{~nm}$, and a weak band with a smooth maximum at $254 \mathrm{~nm}$. Fig. 1 shows that in the studied $\mathrm{pH}$ range of 5.0-9.0, the $\varepsilon$ values of RNTD and NZTD decreased with the increase of the solution $\mathrm{pH}$. This result reflects that the different species of an RNTD and NZTD should have different $\varepsilon$ values at $254 \mathrm{~nm}$. To quantitatively analyze the $\mathrm{pH}$ dependence of UV photolysis of RNTD and NZTD, the $\varepsilon$ was modeled as a function of $\mathrm{pH}$ by assigning each protonated/deprotonated species a specific molar absorptivity $\left(\varepsilon_{0}\right.$ and $\left.\varepsilon_{1}\right)$, with the apparent absorptivity being the summation of the absorptivity contributed by each species (Eqs. (1)-(3)) (Canonica et al., 2008; Bahnmuller et al., 2015). The specific molar absorptivity for each RNTD and NZTD species was fit by minimizing the sum of differences squared between observed and modeled apparent molar absorptivity.

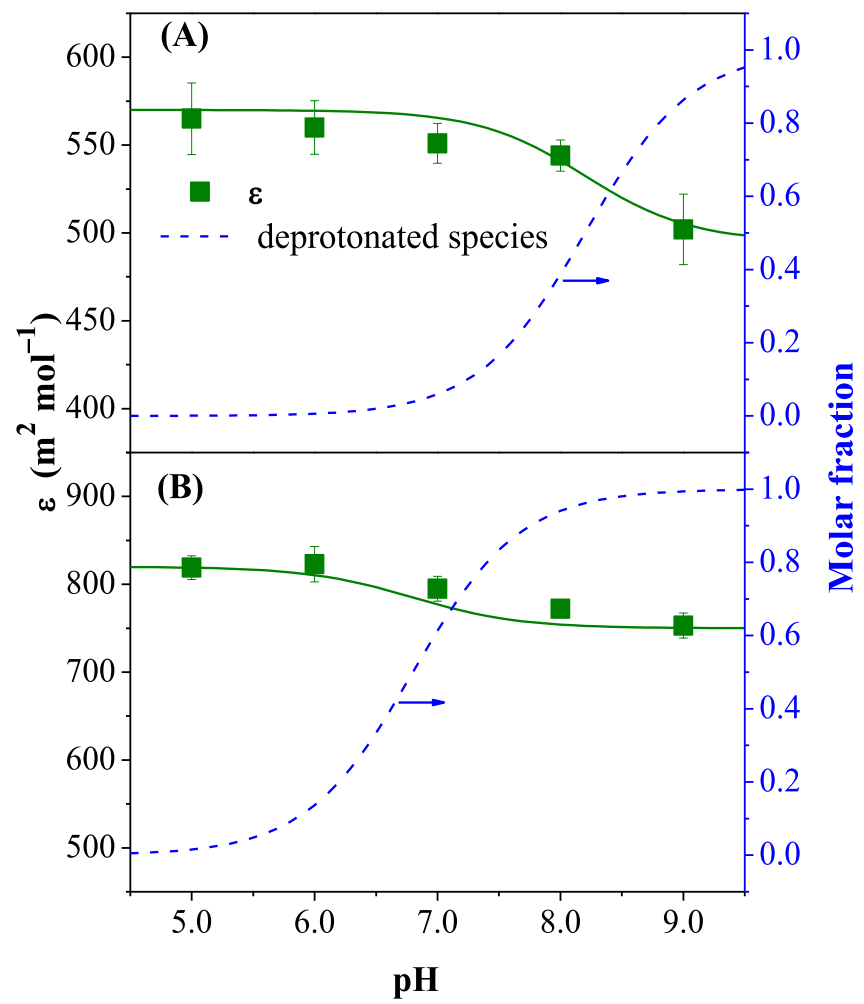

Fig. 1. Molar absorption coefficients $(\varepsilon)$ at $254 \mathrm{~nm}$ and fraction of deprotonated species of RNTD (A) and NZTD (B) as a function of pH. Experimental conditions: [RNTD or NZTD $]_{o}=10 \mu \mathrm{M}$, UV fluence rate $=2.1 \mathrm{~mW} \mathrm{~cm}^{-2}$. Symbols and solid curves represent experimental data and model-fitting results, respectively. Dashed curves represent the fractions of deprotonated RNTD and NZTD. Error bars represent the 95\% confidence interval of triplicate experiments.

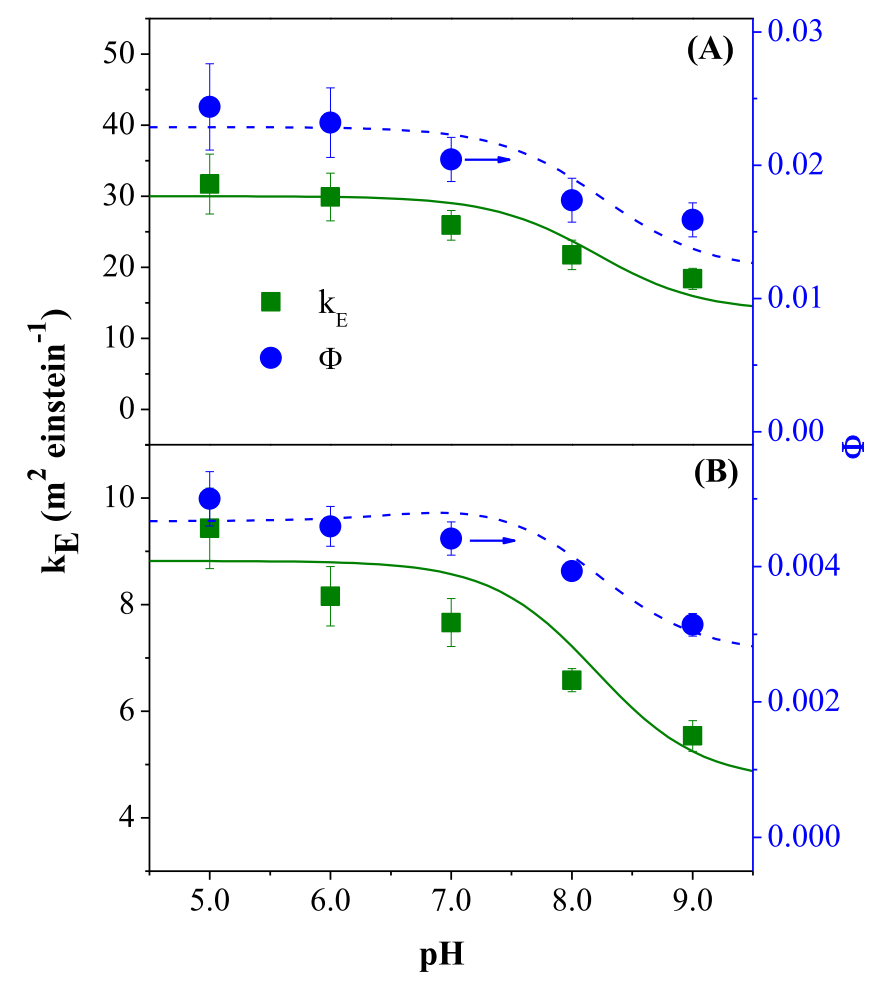

Fig. 2. Apparent photon fluence-based rate constants $\left(k_{E}\right)$ and quantum yields $(\Phi)$ of RNTD (A) and NZTD (B) as a function of $\mathrm{pH}$. Experimental conditions: [RNTD or NZTD $]_{0}=10 \mu \mathrm{M}$, UV fluence rate $=2.1 \mathrm{~mW} \mathrm{~cm}^{-2}$ (or photon fluence rate $=446.8 \mathrm{E} \mathrm{m}^{-2} \mathrm{~s}^{-1}$ ). Symbols and curves (solid and dashed) represent experimental data and model-fitting results, respectively. Error bars represent the $95 \%$ confidence interval of triplicate experiments.

Results indicated that the overall $\varepsilon$ values experimentally measured could be well fitted by Eq. (1), and the specific $\varepsilon$ values were 575 and $820 \mathrm{~m}^{2} \mathrm{~mol}^{-1}$ for neutral species and 491 and $752 \mathrm{~m}^{2} \mathrm{~mol}^{-1}$ for anionic species of RNTD and NZTD, respectively. For water and wastewater treatment, the typical $\mathrm{pH}$ usually ranges from 6.5 to 9.5 , where the neutral and anionic species predominate in RNTD and NZTD solutions.

$\varepsilon=\varepsilon_{0} \alpha_{0}+\varepsilon_{1} \alpha_{1}$

$\alpha_{0}=\frac{1}{1+10^{p H-p K_{a}}}$

$\alpha_{1}=\frac{1}{1+10^{p K_{a}-p H}}$

\subsection{UV photolysis of RNTD and NZTD}

The UV photolysis kinetics at pH 5.0-9.0 of RNTD and NZTD were further investigated. As shown in Figs. S3 and S4, the decrease

Table 1

Specific kinetics parameters for UV photolysis of RNTD and NZTD in aqueous solution at $254 \mathrm{~nm}$

\begin{tabular}{|c|c|c|c|c|c|c|}
\hline \multirow[t]{2}{*}{ Compound } & \multicolumn{2}{|c|}{$\varepsilon\left(\mathrm{m}^{2} \mathrm{~mol}^{-1}\right)$} & \multicolumn{2}{|c|}{$\mathrm{k}\left(\mathrm{m}^{2} \mathrm{E}^{-1}\right)$} & \multicolumn{2}{|l|}{$\Phi$} \\
\hline & $\varepsilon_{0}$ & $\varepsilon_{1}$ & $\mathrm{k}_{0}$ & $\mathrm{k}_{1}$ & $\Phi_{0}$ & $\Phi_{1}$ \\
\hline RNTD & 575 & 491 & 31.90 & 18.53 & 0.022 & 0.012 \\
\hline NZTD & 820 & 752 & 9.49 & 5.64 & 0.0046 & 0.0032 \\
\hline
\end{tabular}


of RNTD and NZTD concentrations as a function of time during the UV photolysis could be described by first-order kinetics, enabling calculation of pseudo-first-order photo degradation rate constants $\left(R^{2}>0.99\right)$. Observed pseudo-first-order rate constants $\left(\mathrm{k}, \mathrm{s}^{-1}\right)$, for RNTD and NZTD were obtained by linear regression of its logarithmic relative residual concentration over photolysis time $t$, according to Eq. (4).

$-\ln C / C_{0}=k t$

To allow a comparison of this study with those using other chemical pollutants by UV photolysis, the fluence-based first-order rate constant $\left(\mathrm{k}_{\mathrm{E}}, \mathrm{m}^{2} \mathrm{~J}^{-1}\right)$ was calculated through Eq. (5) (Canonica et al., 2008; Bahnmuller et al., 2015).

$k_{E}=\frac{k}{E}$

where $\mathrm{E}$ (einstein $\mathrm{m}^{-2} \mathrm{~s}^{-1}$ ) is the photon fluence rate, determined by chemical actinometry.

From Fig. 2, it is clear that the $\mathrm{k}_{\mathrm{E}}$ decreases from $\mathrm{pH} 5.0$ to 9.0. These apparent rate constants were deconvoluted to calculate the specific fluence-based rate constants (Table 1) associated with the neutral and anionic species of the RNTD and NZTD during the UV photolysis with Eq. (6). After these fit parameters had been determined, the $\Phi$ values for the neutral and deprotonated species were determined using Eq. (7). Both the decreasing reactivity of deprotonated RNTD and NZTD with UV is due, in part, to the decreased molar absorptivity of the anionic compared to the neutral form.

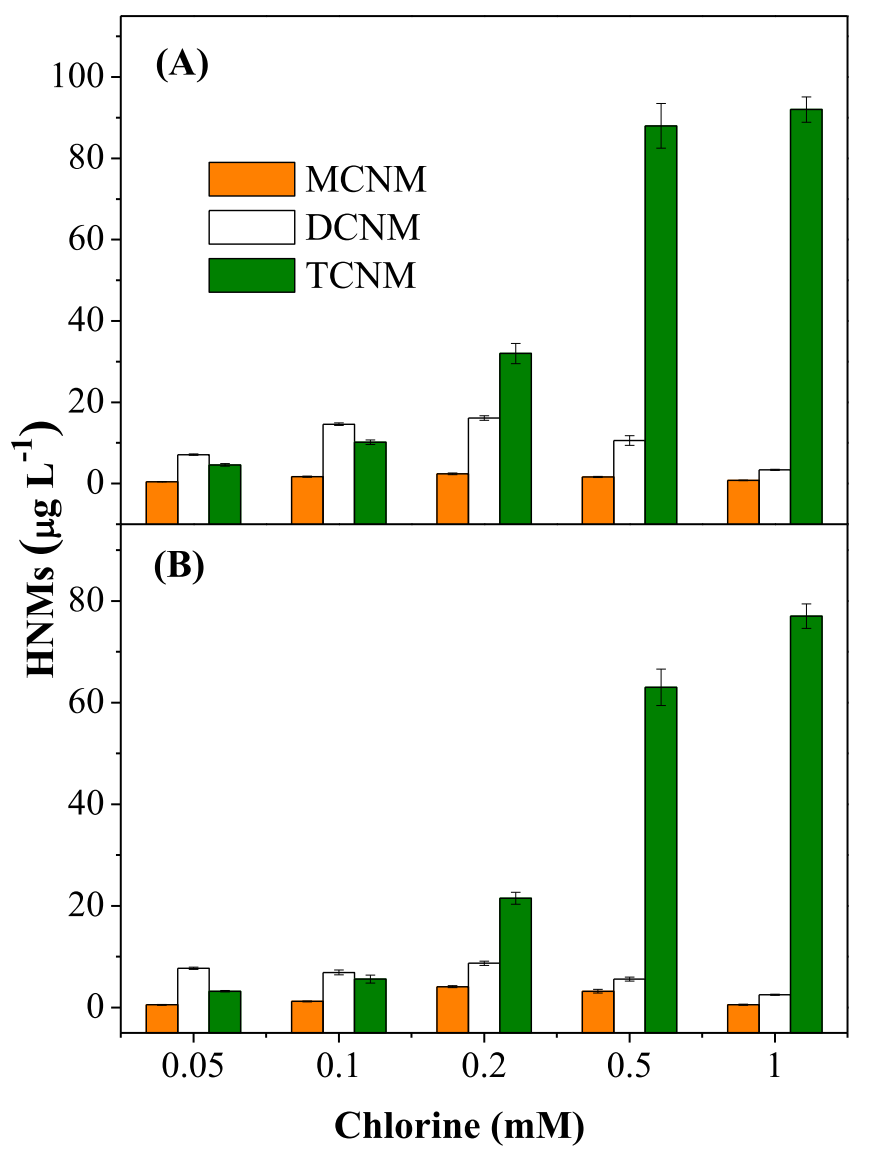

Fig. 3. Effect of initial chlorine concentration on HNMs formation from RNTD (A) and NZTD (B). Experimental conditions: [RNTD or NZTD $]_{o}=10 \mu \mathrm{M}, \mathrm{pH} 7.0$, reaction time $=24 \mathrm{~h}$. Error bars represent the $95 \%$ confidence interval.
This means that both the neutral forms of RNTD and NZTD, which dominate at $\mathrm{pH}$ below the $p K_{\mathrm{a}}$, are more photo-reactive than the deprotonated form. The specific $k_{\mathrm{E}}$ values of RNTD and NZTD vary by one order of magnitude, with a minimum for the anionic form of NZTD $\left(5.64 \mathrm{~m}^{2} \mathrm{E}^{-1}\right)$ and a maximum for the neutral form of RNTD $\left(31.90 \mathrm{~m}^{2} \mathrm{E}^{-1}\right)$. The high $\varepsilon$ and $\mathrm{k}_{\mathrm{E}}$ values at acidic and neutral $\mathrm{pHs}$ indicate that the photo efficiency of the transformation reaction, as measured by $\Phi$ at $254 \mathrm{~nm}$, may be lower under alkaline circumstances.

$k_{E_{p}^{0}}=k_{\mathrm{E}_{p}^{0}, 0} \alpha_{0}+k_{\mathrm{E}_{p}^{0}, 1} \alpha_{1}$

$\Phi=\frac{k_{E}}{2.303 \varepsilon}$

The $\Phi$ values of RNTD and NZTD follow the same trend, decreased with the increase of $\mathrm{pH}$. As shown in Table 1 , the $\Phi$ values for neutral and anionic species of RNTD were 0.022 and 0.012 , respectively (3.8 and 2.8 fold higher than those of NZTD, respectively), accounting for the faster degradation during the UV photolysis. The $\mathrm{pH}$ dependence of $\Phi$ might result from the acidbase speciation of excited-state species or from acid-catalyzed deactivation of photolysis intermediates. Meanwhile, the $\Phi$ values of RNTD and NZTD were higher than those of carbamazepine (Wols and Hofman-Caris, 2012), naproxen (Pereira et al., 2007), and 2,4-dichlorophenoxyacetic acid (Chu, 2001), while lower than those of diclofenac (Shu et al., 2013) and sulfamethoxazole (Lian et al., 2015), indicating a moderate UV photolysis rate of RNTD and NZTD. With these rate constants, the apparent transformation kinetics of the RNTD and NZTD can be determined

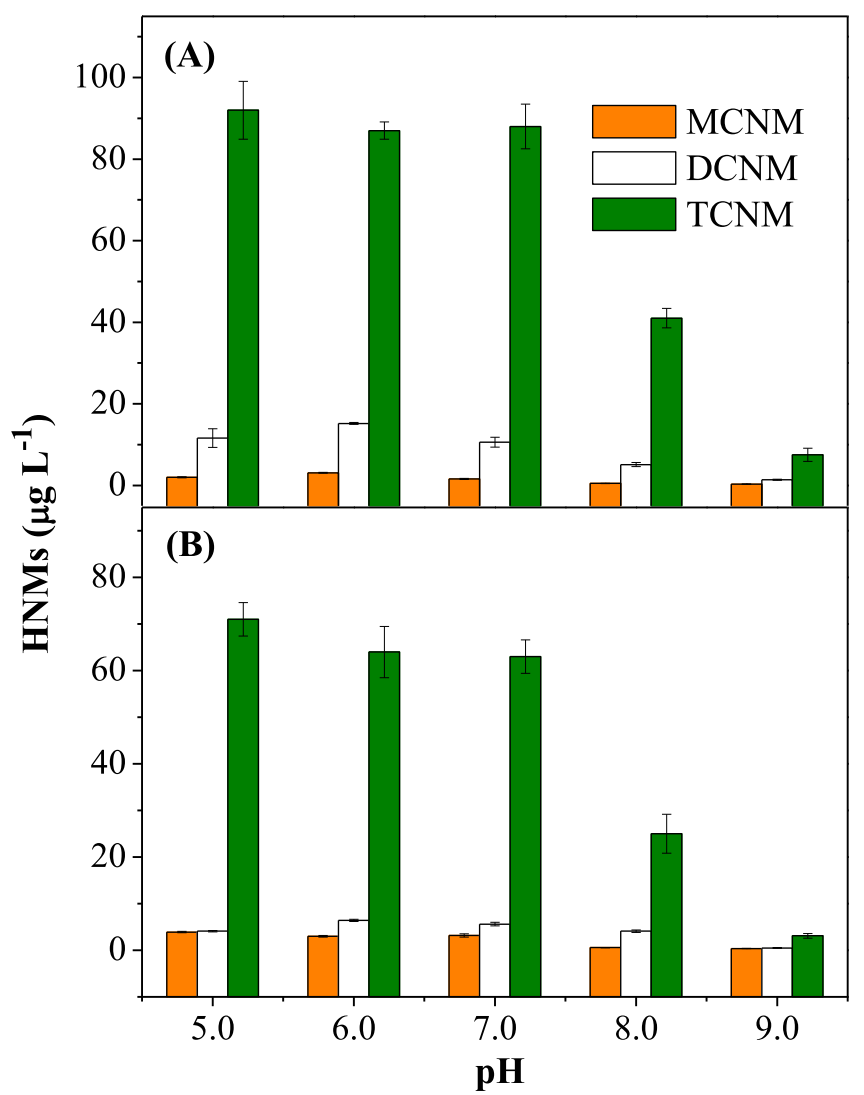

Fig. 4. Effect of pH on HNMs formation during chlorination of RNTD (A) and NZTD (B). Experimental conditions: [RNTD or NZTD $]_{o}=10 \mu \mathrm{M}$, [chlorine $]_{o}=0.5 \mathrm{mM}$, reaction time $=24 \mathrm{~h}$. Error bars represent the 95\% confidence interval. 


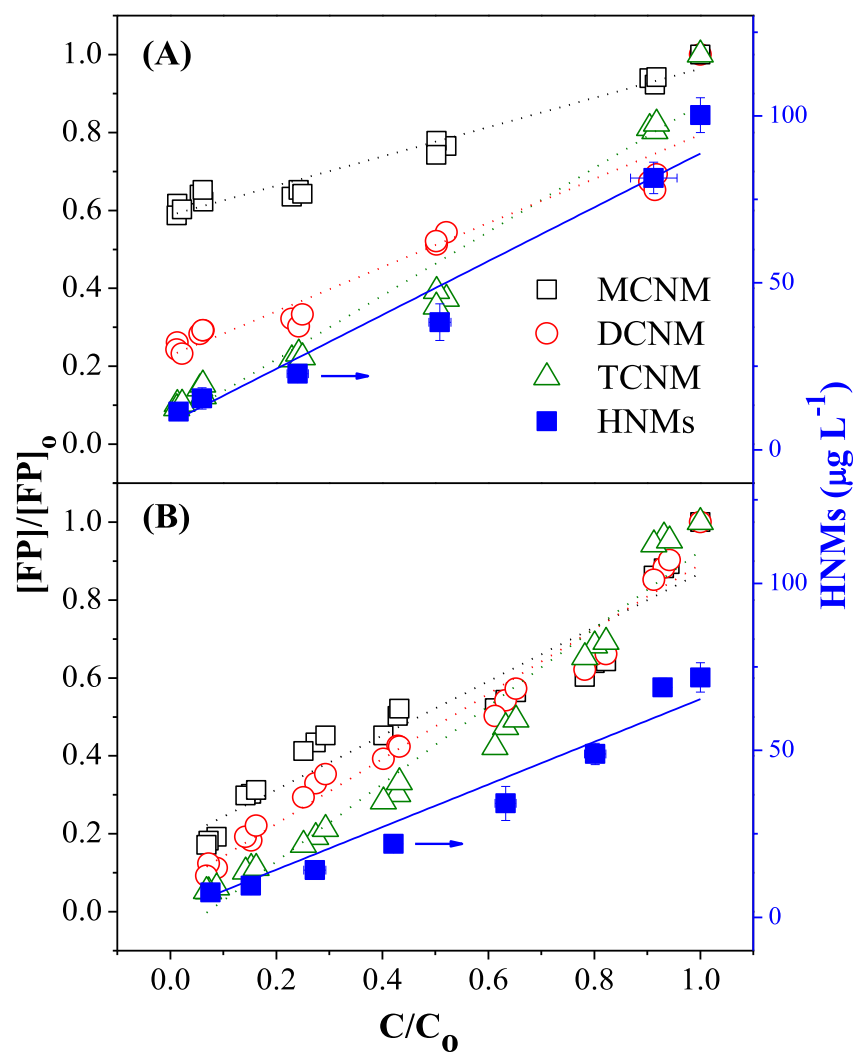

Fig. 5. Plot of normalized formation potential of MCNM, DCNM, TCNM and HNMs $\left([\mathrm{FP}] /[\mathrm{FP}]_{0}\right)$ vs. normalized residual concentration $\left(\mathrm{C} / \mathrm{C}_{0}\right)$ of RNTD $(\mathrm{A})$ and NZTD (B) during UV photolysis. Error bars represent the 95\% confidence interval.

for any water/wastewater $\mathrm{pH}$, providing an estimate of baseline removal by UV photolysis. Note that the mineralization of RNTD and NZTD during the UV photolysis may be rather limited as no oxidant was added during the photolysis. Thus, the HNMsFP may increase with the cleavage of chemical bond and TBPs formation, which needs a further HNMsFP evaluation before and after the UV photolysis.

\subsection{HNMSFP of RNTD and NZTD}

The effect of initial chlorine concentration on the HNMs formation from RNTD and NZTD was firstly investigated. As shown in Fig. 3, the initial chlorine concentration impacts not only the formed HNMs species, but also the HNMs formation amounts. DCNM was the dominated HNMs species formed when the molar ratio of [Chlorine]/[RNTD or NZTD] $\leq 10$. However, TCNM became the dominated formed HNMs species with the increase of chlorine concentration. With the chlorine concentration increased from 0.05 to $1.0 \mathrm{mM}$, the TCNM concentration increased from $4.6 \pm 0.33$ to $92.0 \pm 3.1 \mu \mathrm{g} \mathrm{L}^{-1}$ and from $3.2 \pm 0.16$ to $77 \pm 2.4 \mu \mathrm{g} \mathrm{L}^{-1}$ for RNTD and NZTD, respectively. Thus, a $0.5 \mathrm{mM}$ chlorine concentration was adopted in the HNMsFP test based on these results and previous studies (Bond et al., 2014; Wang et al., 2016).

$\mathrm{pH}$ is another important factor governing the formation of DBPs by influencing on $\mathrm{HOCl} / \mathrm{OCl}^{-}$species, halogenation and hydrolysis reactions during chlorination. As shown in Fig. 4, the solution $\mathrm{pH}$ significantly affected the HNM formation amounts. The highest TCNM formation was found under acidic and neutral circumstances, which is different from the previous results (Joo and Mitch, 2007; Chiang et al., 2010). There are no obvious differences among the HNM yields at pH 5.0-7.0, while the HNM formation amounts decreased in alkaline circumstance with the minimum value of 9.2 and $4.0 \mu \mathrm{g} \mathrm{L}^{-1}$ at $\mathrm{pH} 9.0$ for RNTD and NZTD, respectively. The $\mathrm{pK}_{\mathrm{a}}$ of RNTD, NZTD and $\mathrm{HOCl}$ were 8.7, 6.8, and 7.5, respectively (Degim et al., 2001; Tian et al., 2014). As RNTD and NZTD are prone precursors of HNMs during chlorination, it is speculated that the both the neutral and anionic species of RNTD and NZTD contributed to the HNMs formation. However, the fraction of active chlorine species at different $\mathrm{pH}$ seems to determine the HNMs formation amount (Hansen et al., 2012). Meanwhile, the stability of HNMs, are subject to be influenced by $\mathrm{pH}$. Joo and Mitch (2007) reported that TCNM was stable at pH 5.0, whereas it decomposed rapidly at $\mathrm{pH}$ 9.0. Moreover, the precursors of HNMs were also unstable under alkaline circumstances, which may restrict HNMs formation during chlorination (Yang et al., 2010).

Based on the results above, a HNMsFP test method was developed (i.e., [chlorine $]_{0}=0.5 \mathrm{mM}, \mathrm{pH} 7.0,25^{\circ} \mathrm{C}$, and after $24 \mathrm{~h}$ ) to investigate the variation of HNMsFP during the UV photolysis of RNTD and NZTD. It was found that the molar yields of HNMs from RNTD and NZTD at pH 7.0 were $5.6 \pm 0.3 \%$ and $4.7 \pm 0.4 \%$, respectively under this method. Wang et al. (2016) reported a comparable result for the conversion of RNTD and NZTD to HNMs ( $5.8 \pm 0.6 \%$ for RNTD and $5.0 \pm 1.1 \%$ for NZTD). Although both the chemical structures of RNTD and NZTD contain two secondary amine groups (i.e., one primary amine group and one nitro group), the molar yield of HNMs from the chlorination of amine group was rather low $(\leq 0.04 \pm 0.01 \%$ ), probably due to the weak oxidation ability of chlorine and the slow transformation of amine group into nitro group (Bond et al., 2014). Thus, the nitro group in RNTD and NZTD is speculated to the prone functional group for HNMs formation during the chlorination.

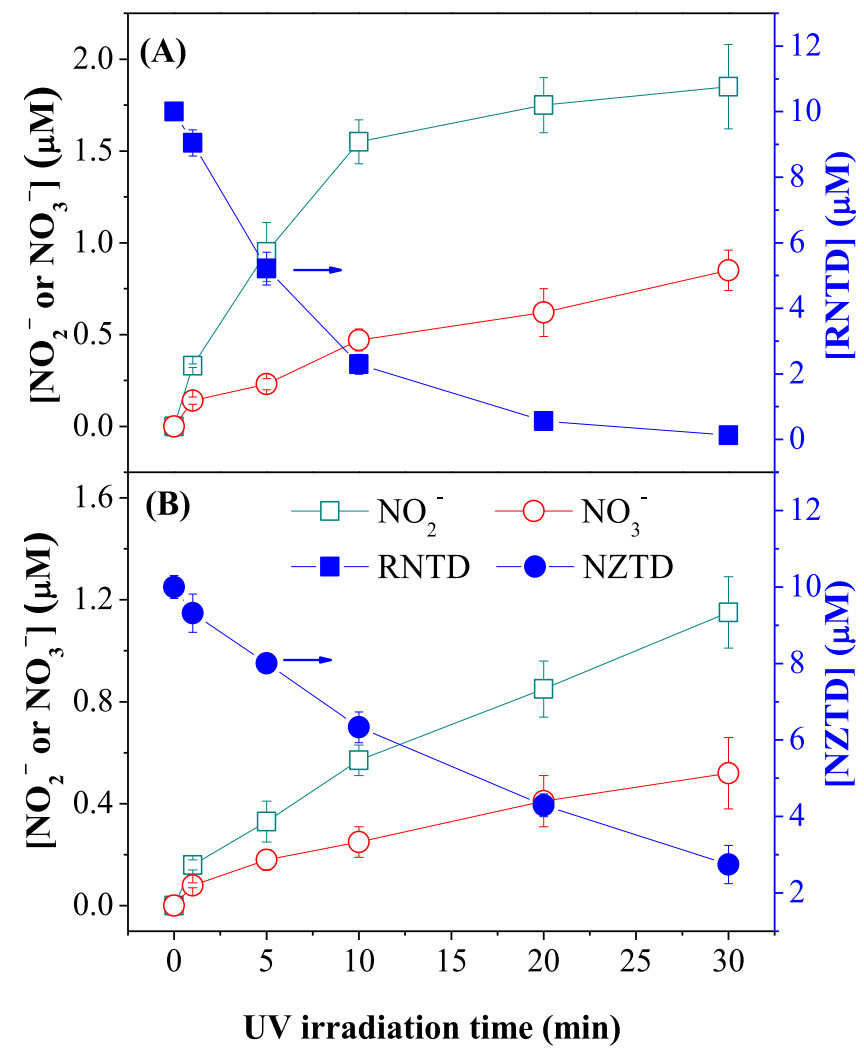

Fig. 6. Formation of $\mathrm{NO}_{2}^{-}$and $\mathrm{NO}_{3}^{-}$ions during UV photolysis of RNTD (A) and NZTD (B). Experimental conditions: [RNTD or NZTD $]_{0}=10 \mu \mathrm{M}$, UV fluence rate $=2.1 \mathrm{~mW} \mathrm{~cm}^{-2}$. Error bars represent the $95 \%$ confidence interval. 


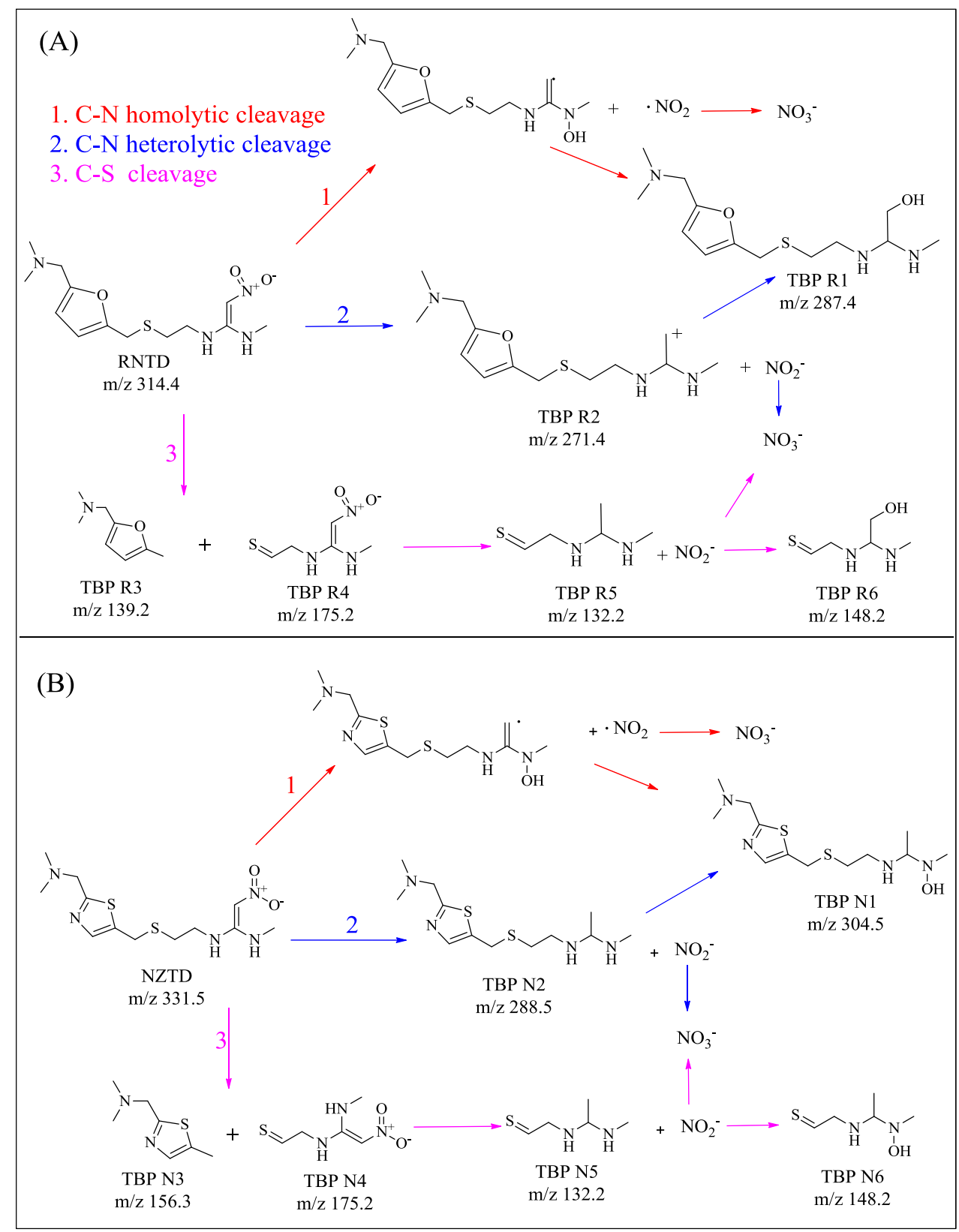

Fig. 7. Proposed degradation pathways of RNTD (A) and NZTD (B) during UV photolysis.

\subsection{Effect of UV photolysis on HNMsFP}

The role of UV photolysis on the HNMsFPs of RNTD and NZTD were further investigated by measuring the residual HNMsFP during their degradation at $\mathrm{pH}$ 7.0. As shown in Fig. 5, the sum of HNMsFP including MCNM, DCNM and TCNM decreased linearly with the decreasing RNTD and NZTD concentrations $\left(R^{2}>0.97\right)$. The HNMsFP from RNTD and NZTD were significantly reduced by UV photolysis and a more effective reduction of HNMsFP from RNTD was observed than those of NZTD under the same UV fluence. For example, the HNMsFP from RNTD were reduced to $<5 \%$, while the remained HNMsFP from NZTD remained $40 \%$ of the initial formation after $30 \mathrm{~min}$, which was consistent with the degradation kinetics of RNTD and NZTD during the UV photolysis.

The regression results indicated that the mother structure of
RNTD and NZTD played an important role for the HNMs formation during chlorination. Once the mother structure of RNTD and NZTD was destroyed by UV photolysis, the HNMsFP decreased simultaneously. As mentioned above, the nitrogen source of HNMs during chlorination of RNTD and NZTD was inferred to the nitro group of RNTD and NZTD. Thus, it was speculated that the attack on the nitro group of RNTD and NZTD by UV photolysis induced the reduction of HNMsFP and other denitrated TBPs have negligible contributions to HNMs formation compared with RNTD and NZTD. To verify this speculation, the formed anions during the UV photolysis of RNTD and NZTD were investigated and obvious $\mathrm{NO}_{2}^{-}$and $\mathrm{NO}_{3}^{-}$ion formations were observed. As shown in Fig. 6, the $\mathrm{NO}_{2}^{-}$and $\mathrm{NO}_{3}^{-}$ concentrations increased quickly following the degradation of RNTD and NZTD in the initial stages of photolysis (0-10 min) and remained at constant level at later phase. During the photolysis of 


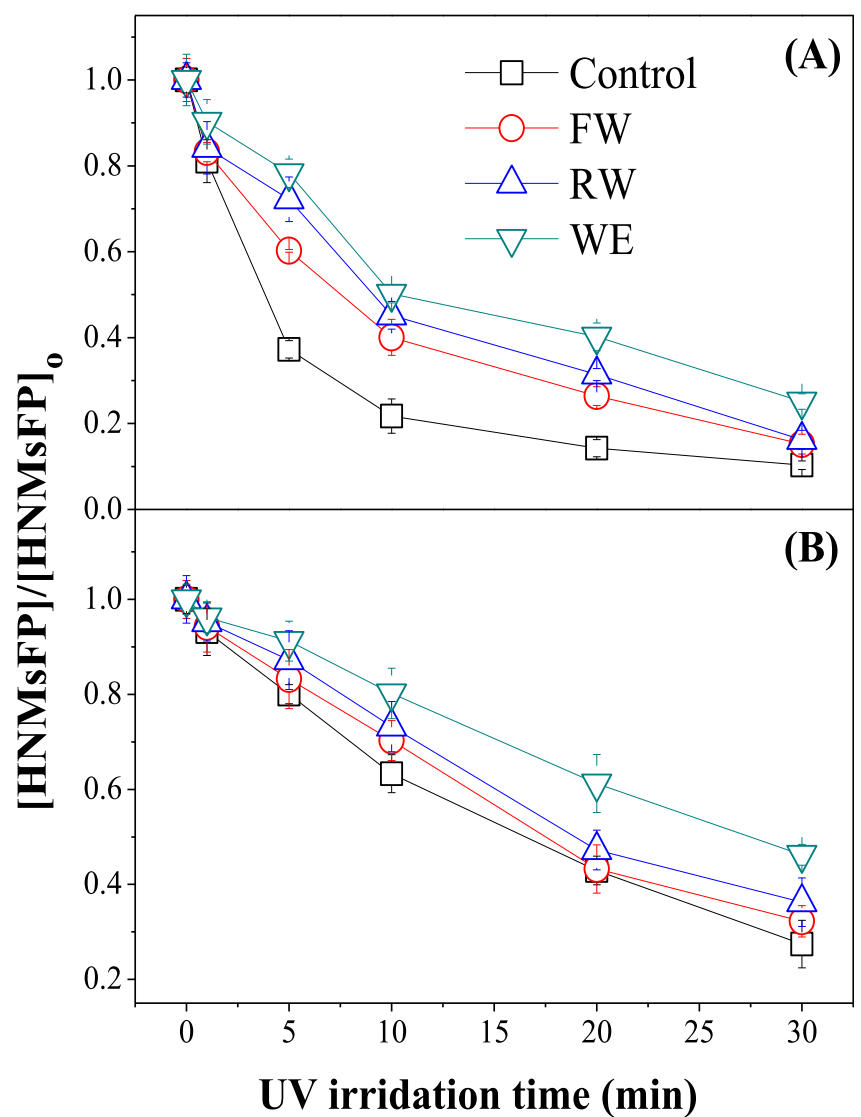

Fig. 8. Change of HNMsFP after UV photolysis of RNTD (A) and NZTD (B) spiked in three real waters for different times. Experimental conditions: [RNTD or $\mathrm{NZTD}]_{\mathrm{o}}=10 \mu \mathrm{M}$, UV fluence rate $=2.1 \mathrm{~mW} \mathrm{~cm}^{-2}$. Error bars represent the $95 \%$ confidence interval. FW: filtered water; RW: river water; WE: wastewater treatment plant effluent water.

RNTD and NZTD, the $\mathrm{NO}_{2}^{-}$concentration was always higher than $\mathrm{NO}_{3}^{-}$concentration. Xu et al. (2009) observed similar results at neutral $\mathrm{pH}$ also, i.e., the concentration of $\mathrm{NO}_{3}^{-}$produced was much lower than that of $\mathrm{NO}_{2}^{-}$during the photolysis of nitroso-containing compounds. The formation of $\mathrm{NO}_{3}^{-}$may be derived from the oxidation of $\mathrm{NO}_{2}^{-}$. However, the limited artificial oxidant and radical during the UV photolysis may restrict the $\mathrm{NO}_{3}^{-}$formation.

\subsection{Degradation pathways of RNTD and NZTD during UV photolysis}

The UV photolysis could induce the transformation of compound via photoelimination, photoreduction, photoaddition, and photohydrolysis (Fang et al., 2013). The dissociation energies of $\mathrm{C}-\mathrm{N}$ and $\mathrm{C}-\mathrm{S}$ bonds are 306 and $272 \mathrm{~kJ} \mathrm{~mol}^{-1}$, respectively, significantly lower than those of $\mathrm{C}-\mathrm{H}, \mathrm{N}-\mathrm{H}$ and $\mathrm{C}-\mathrm{C}$ bonds (McMurry, 2008). Therefore, the main TBPs of RNTD and NZTD by UV photolysis could be produced from $\mathrm{C}-\mathrm{N}$ and $\mathrm{C}-\mathrm{S}$ bond fissions (Table S1). Combined with TBPs analysis, three photolytic pathways of RNTD and NZTD are proposed in Fig. 7A and Fig. 7B, respectively. The first pathway was the homolytic cleavage of $\mathrm{C}-\mathrm{N}$ bond without deprotonation, which generated the methyl radical and $\mathrm{NO}_{2}$ radical. Then the intermediate underwent acid-catalyzed hydrolysis to form TBP R1 and TBP $\mathrm{N} 1$ and the $\mathrm{NO}_{2}$ radical was released as $\mathrm{NO}_{2}^{-}$(Phillips et al., 2005; Cole et al., 2007). The second pathway was the heterolytic cleavage of $\mathrm{C}-\mathrm{N}$ bond, which produced TBP R2 and TBP $\mathrm{N} 2$ and $\mathrm{NO}_{2}^{-}$ion as the result of a nucleophile attack in aqueous solution, which was facilitated by the nucleophilic attack of a water molecule in the nitro group. As mentioned above, the $\mathrm{NO}_{3}^{-}$formation derived from the oxidation of $\mathrm{NO}_{2}^{-}$even if the formation amount is not obvious. Stefan and Bolton (2002) also observed $\mathrm{NO}_{3}^{-}$was generated along with the $\mathrm{NO}_{2}^{-}$during the UV photolysis of $\mathrm{N}$-Nitrosodimethylamine, but at a lower level than $\mathrm{NO}_{2}^{-}$. The third pathway may involve the cleavage of $\mathrm{C}-\mathrm{S}$ bond. Then the TBP R4 and TBP N4 may undergo the similar homolytic and heterolytic denitration pathways, with the TBP R6, TBP N6, $\mathrm{NO}_{2}^{-}, \mathrm{NO}_{3}^{-}$formations subsequently (Fang et al., 2013). Note that the inter-transformation between $\mathrm{NO}_{3}^{-}$and $\mathrm{NO}_{2}^{-}$may occur during the UV photolysis. Complementary experiments with the tested UV fluence in this study were conducted and it was found that both the concentrations of $\mathrm{NO}_{3}^{-}$and $\mathrm{NO}_{2}^{-}$kept stable during the UV photolysis (data not shown). Overall, the denitration occurred among all the three proposed pathways, which contributed to the simultaneous reduction of HNMsFP during the photolysis of RNTD and NZTD.

\subsection{Effect of water matrix}

To investigate the effect of UV photolysis on the HNMsFP of RNTD and NZTD in real waters, three real water samples (including FW, RW and WE with their water qualities shown in Table S2) were spiked with $10 \mu \mathrm{M}$ RNTD or NZTD. Prior to irradiation, the $\mathrm{pH}$ of the samples was adjusted to 7.0 to allow direct comparison with control group (ultrapure water). As expected, the degradation of RNTD was much faster than that of NZTD in the real water. Also, all the degradation rate constants of the RNTD and NZTD in the real water samples were lower than those in the ultrapure water followed the descending order of $\mathrm{FW}>\mathrm{RW}>\mathrm{WE}$ (data not shown). The reduced degradation rates of RNTD and NZTD in the real water samples should be primarily attributable to the presence of natural organic matter via acting as an inner filter to reduce the effective fluence rate, and consequently the rate of any photochemical reaction (Latch et al., 2003; Wammer et al., 2013). As shown in Fig. 8, the HNMsFP reductions in real waters by UV photolysis were also lower to those in the ultrapure water with a reduction of the HNMsFP by 55.6-86.0\% (FW > RW > WE).

UV-based processes are increasingly adopted not only for disinfection of water and wastewater, but also for the treatment of emerging pollutants which can be furthermore configured to generate reactive species through photo chemical and photo catalytic reactions. This study determined the fundamental parameters for the UV photolysis of RNTD and NZTD (including $\varepsilon, \mathrm{k}_{\mathrm{E}}$, and $\Phi$ ), which can be extended to other UV systems to predict degradation kinetics. In China, the UV fluences for disinfection of wastewater, drinking water and reclaimed water are regulated as 20,40 and $80 \mathrm{~mJ} \mathrm{~cm}^{-2}$, respectively (GB/T 19837-2005, UV Disinfection Equipment for Municipal Water and Wastewater Treatment). At a typical pH of 7.0, the removal efficiencies of RNTD and NZTD in these three waters during UV disinfection were estimated to be $<70 \%$. Obviously, all the mandatory disinfection UV fluences in different waters cannot achieve the effective abatement of RNTD, NZTD and their HNMsFP, highlighting the necessity of increasing UV fluence or developing UV-based advanced oxidation process in future.

\section{Conclusions}

Based on the experimental results, the following conclusions can be drawn:

- Both the RNTD and NZTD are photo-reactive under UV irradiation and exhibit pH-dependent degradation rates at pH 5.0-9.0, in accordance to their deprotonation equilibria. 
- The specific $\mathrm{k}_{\mathrm{E}}$ were obtained with a minimum for the anionic NZTD (5.64 $\mathrm{m}^{2} \mathrm{E}^{-1}$ ) and a maximum for the neutral RNTD $\left(31.90 \mathrm{~m}^{2} \mathrm{E}^{-1}\right)$.

- Both the RNTD and NZTD are prone precursors of HNMs with molar yields of $5.6 \pm 0.3 \%$ and $4.7 \pm 0.4 \%$, respectively at $\mathrm{pH} 7.0$ and acidic and neutral circumstances facilitated the HNMs formation.

- The UV photolysis of RNTD and NZTD could reduce their HNMsFP simultaneously and denitration accounted for this reduction.

\section{Acknowledgment}

This work was financially supported by the National Natural Science Foundation of China (51408590, 51290281, 51525806), Chinese Academy of Sciences (QYZDY-SSW-DQC004) and CASSAFEA International Partnership Program for Creative Research Teams.

\section{Appendix A. Supplementary data}

Supplementary data related to this article can be found at http:// dx.doi.org/10.1016/j.watres.2017.04.049.

\section{References}

Bahnmuller, S., Loi, C.H., Linge, K.L., von Gunten, U., Canonica, S., 2015. Degradation rates of benzotriazoles and benzothiazoles under UV-C irradiation and the advanced oxidation process $\mathrm{UV} / \mathrm{H}_{2} \mathrm{O}_{2}$. Water Res. 74, 143-154.

Bolton, J.R., Linden, K.G., 2003. Standardization of methods for fluence (UV dose) determination in bench-scale UV experiments. J. Environ. Eng. 129 (3), 209-215.

Bond, T., Templeton, M.R., Graham, N., 2012. Precursors of nitrogenous disinfection by-products in drinking water-a critical review and analysis. J. Hazard. Mater: 235-236, 1-16.

Bond, T., Kamal, N.H.M., Bonnisseau, T., Templeton, M.R., 2014. Disinfection byproduct formation from the chlorination and chloramination of amines. J. Hazard. Mater. 278, 288-296.

Bond, T., Templeton, M.R., Kamal, N.H.M., Graham, N., Kanda, R., 2015. Nitrogenous disinfection byproducts in English drinking water supply systems: occurrence, bromine substitution and correlation analysis. Water Res. 85, 85-94.

Canonica, S., Meunier, L., von Gunten, U., 2008. Phototransformation of selected pharmaceuticals during UV treatment of drinking water. Water Res. 42 (1-2), $121-128$.

Castiglioni, S., Bagnati, R., Fanelli, R., Pomati, F., Calamari, D., Zuccato, E., 2006. Removal of pharmaceuticals in sewage treatment plants in Italy. Environ. Sci. Technol. 40 (1), 357-363.

Chiang, P.C., Chang, E.E., Chuang, C.C., Liang, C.H., Huang, C.P., 2010. Evaluating and elucidating the formation of nitrogen-contained disinfection by-products during pre-ozonation and chlorination. Chemosphere 80 (3), 327-333.

Chu, W., 2001. Modeling the quantum yields of herbicide 2,4-D decay in $\mathrm{UV} / \mathrm{H}_{2} \mathrm{O}_{2}$ process. Chemosphere 44 (5), 935-941.

Chu, W.H., Gao, N.Y., Templeton, M.R., Yin, D.Q., 2011. Comparison of inclined plate sedimentation and dissolved air flotation for the minimisation of subsequent nitrogenous disinfection by-product formation. Chemosphere 83 (5), 647-651.

Chu, W.H., Li, D.M., Gao, N.Y., Templeton, M.R., Tan, C.Q., Gao, Y.Q., 2014. The control of emerging haloacetamide DBP precursors with UV/persulfate treatment. Water Res. 72 (SI), 340-348.

Cole, S.K., Cooper, W.J., Fox, R.V., Gardinali, P.R., Mezyk, S.P., Mincher, B.J., O'Shea, K.E., 2007. Free radical chemistry of disinfection byproducts. 2. Rate constants and degradation mechanisms of trichloronitromethane (chloropicrin). Environ. Sci. Technol. 41 (3), 863-869.

Degim, T., Zaimoglu, V., Akay, C., Degim, Z., 2001. pH-Metric log K calculations of famotidine, naproxen, nizatidine, ranitidine and salicylic acid. Farmaco 56 (9), 659-663.

Deng, L., Huang, C.H., Wang, Y.L., 2014. Effects of combined UV and chlorine treatment on the formation of trichloronitromethane from amine precursors. Environ. Sci. Technol. 48 (5), 2697-2705.

Fang, J.Y., Ma, J., Yang, X., Shang, C., 2010. Formation of carbonaceous and nitrogenous disinfection by-products from the chlorination of Microcystis aeruginosa. Water Res. 44 (6), 1934-1940.

Fang, J.Y., Ling, L., Shang, C., 2013. Kinetics and mechanisms of pH-dependent degradation of halonitromethanes by UV photolysis. Water Res. 47 (3),
$1257-1266$.

Garoma, T., Gurol, M.D., 2005. Modeling aqueous ozone/UV process using oxalic acid as probe chemical. Environ. Sci. Technol. 39 (20), 7964-7969.

Hansen, K.M.S., Willach, S., Mosbaek, H., Andersen, H.R., 2012. Particles in swimming pool filters - does pH determine the DBP formation? Chemosphere 87 (3), 241-247.

Joo, S.H., Mitch, W.A., 2007. Nitrile, aldehyde, and halonitroalkane formation during chlorination/chloramination of primary amines. Environ. Sci. Technol. 41 (4) 1288-1296.

Kolpin, D.W., Furlong, E.T., Meyer, M.T., Thurman, E.M., Zaugg, S.D., Barber, L.B. Buxton, H.T., 2002. Pharmaceuticals, hormones, and other organic wastewater contaminants in U.S. streams, 1999-2000: a national reconnaissance. Environ. Sci. Technol. 36 (6), 1202-1211.

Latch, D.E., Stender, B.L., Packer, J.L., Arnold, W.A., McNeill, K., 2003. Photochemical fate of pharmaceuticals in the environment: cimetidine and ranitidine. Environ. Sci. Technol. 37 (15), 3342-3350.

Lee, W., Westerhoff, P., 2006. Dissolved organic nitrogen removal during water treatment by aluminum sulfate and cationic polymer coagulation. Water Res. 40 (20), 3767-3774

Lian, J.F., Qiang, Z.M., Li, M.K., Bolton, J.R., Qu, J.H., 2015. UV photolysis kinetics of sulfonamides in aqueous solution based on optimized fluence quantification. Water Res. 75, 43-50.

McCurry, D.L., Quay, A.N., Mitch, W.A., 2016. Ozone promotes chloropicrin formation by oxidizing amines to nitro compounds. Environ. Sci. Technol. 50 (3), 1209-1217.

McMurry, J., 2008. Organic Chemistry. Thomson Brooks/Cole, California, U.S.

Munch, D.J., Hautman, D.P., 1995. EPA Method 551.1 Determination of Chlorination Disinfection Byproducts, Chlorinated Solvents, and Halogenated Pesticides/ Herbicides in Drinking Water by Liquid-liquid Extraction and Gas Chromatography with Electron-capture Detection, Revision 1.0. United States Environmental Protection Agency, Cincinnati, OH.

Pereira, V.J., Weinberg, H.S., Linden, K.G., Singer, P.C., 2007. UV degradation kinetics and modeling of pharmaceutical compounds in laboratory grade and surface water via direct and indirect photolysis at $254 \mathrm{~nm}$. Environ. Sci. Technol. 41 (5), 1682-1688.

Phillips, D.L., Zhao, C., Wang, D., 2005. A theoretical study of the mechanism of the water-catalyzed $\mathrm{HCl}$ elimination reactions of $\mathrm{CHXCl}(\mathrm{OH})(\mathrm{X}=\mathrm{H}, \mathrm{Cl})$ and $\mathrm{HClCO}$ in the gas phase and in aqueous solution. J. Phys. Chem. A 109 (42), 9653-9673.

Plewa, M.J., Wagner, E.D., Jazwierska, P., Richardson, S.D., Chen, P.H., McKague, A.B. 2004. Halonitromethane drinking water disinfection byproducts: chemical characterization and mammalian cell cytotoxicity and genotoxicity. Environ. Sci. Technol. 38 (1), 62-68.

Radjenovic, J., Petrovic, M., Barceló, D., 2009. Fate and distribution of pharmaceuticals in wastewater and sewage sludge of the conventional activated sludge (CAS) and advanced membrane bioreactor (MBR) treatment. Water Res. 43 (3), $831-841$.

Shu, Z.Q., Bolton, J.R., Belosevic, M., El Din, M.G., 2013. Photodegradation of emerging micropollutants using the medium-pressure $\mathrm{UV} / \mathrm{H}_{2} \mathrm{O}_{2}$ advanced oxidation process. Water Res. 47 (8), 2881-2889.

Stefan, M.I., Bolton, J.R., 2002. UV direct photolysis of N-nitrosodimethylamine (NDMA): kinetic and product study. Helv. Chim. Acta 85 (5), 1416-1426.

Tian, F., Liu, W.J., Guo, G., Qiang, Z.M., Zhang, C., 2014. Kinetics and mechanism of dimethoate chlorination during drinking water treatment. Chemosphere 103, $181-187$.

Wammer, K.H., Korte, A.R., Lundeen, R.A., Sundberg, J.E., McNeill, K., Arnold, W.A., 2013. Direct photochemistry of three fluoroquinolone antibacterials: norfloxacin, ofloxacin, and enrofloxacin. Water Res. 47 (1), 439-448.

Wang, X.F., Zhou, B.H., Yang, H.W., Wang, X.M., Xie, Y.F., 2016. Effect of oxidation on nitro-based pharmaceutical degradation and trichloronitromethane formation. Chemosphere 146, 154-161.

Weinberg, H.S., Krasner, S.W., Richardson, S.D., Thruston Jr., A.D., 2002. The Occurrence of Disinfection By-products (DBPs) of Health Concern in Drinking Water: Results of a Nationwide DBP Occurrence Study. EPA/600/R02/068.

Wols, B.A., Hofman-Caris, C.H.M., 2012. Review of photochemical reaction constants of organic micropollutants required for UV advanced oxidation processes in water. Water Res. 46 (9), 2815-2827.

Wu, S.M., Ho, Y.H., Wu, H.L., Chen, S.W., Ko, H.S., 2001. Head-column field-amplified sample stacking in capillary electrophoresis for the determination of cimetidine, famotidine nizatidine and ranitidine- $\mathrm{HCl}$ in plasma. Electrophoresis 22 (13), 2717-2722.

Xu, B.B., Chen, Z.L., Qi, F., Shen, J.M., Wu, F.C., 2009. Factors influencing the photodegradation of $\mathrm{N}$-nitrosodimethylamine in drinking water. Front. Eev. Sci. Eeg 3 (1), 91-97.

Yang, X., Fan, C.H., Shang, C., Zhao, Q., 2010. Nitrogenous disinfection byproducts formation and nitrogen origin exploration during chloramination of nitrogenous organic compounds. Water Res. 44 (9), 2691-2702.

Yang, X., Shen, Q.Q., Guo, W.H., Peng, J.F., Liang, Y.M., 2012. Precursors and nitrogen origins of trichloronitromethane and dichloroacetonitrile during chlorination/ chloramination. Chemosphere 88 (1), 25-32. 